\title{
DISCURSO EN OCASIÓN DEL DOCTORADO HONORIS CAUSA POR LA UNIVERSIDAD AutónOMA dE SAN LUIS Potosí
}

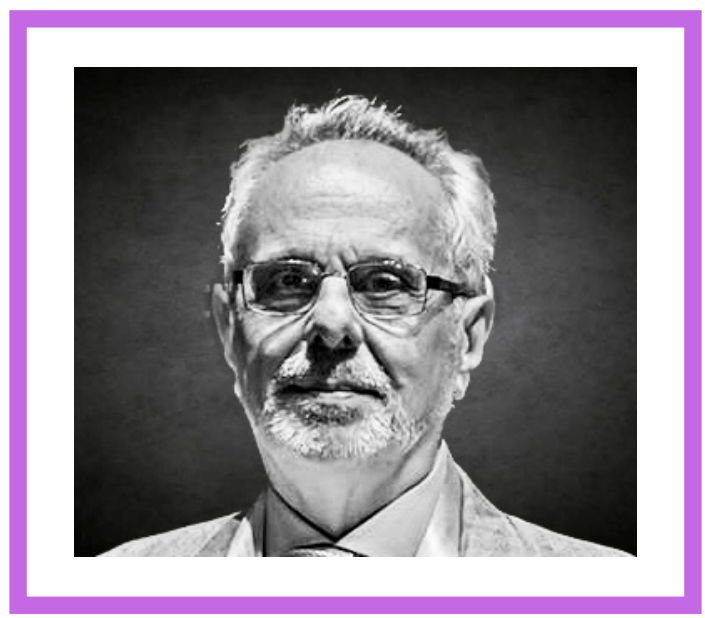

\author{
Emilio Ribes Iñesta \\ Centro de Estudios e Investigaciones en Conocimiento y Aprendizaje Humano \\ Universidad Veracruzana
}

\begin{abstract}
El Dr. Emilio Ribes Iñesta es Licenciado en Psicología por la Universidad Nacional Autónoma de México, Maestro en Psicología Experimental por la Universidad de Toronto (Canadá), y Doctor en Filosofía por la Universidad Nacional Autónoma de México. El Dr. Ribes cuenta con perfil PROMEP y ha sido distinguido con el Nivel III del Sistema Nacional de Investigadores del Consejo Nacional de Ciencia y Tecnología y actualmente tiene el reconocimiento de Investigador Emérito. Ha ejercido la docencia a nivel licenciatura, maestría y doctorado en diversas universidades, en las cuales ha sido responsable directo del Programa de estudios implicado (Ribes, 2010).

Ver más...

\section{PRESENTACIÓN DEL DiscuRso}

Se presenta el discurso del Dr. Emilio Ribes Iñesta en ocasión del reconocimiento Doctorado Honoris Causa por la Universidad Autónoma de San Luis Potosí (UASLP), por sus importantes aportaciones en el estudio del comportamiento humano y de la psicología, a nivel nacional e internacional. El reconocimiento fue entregado en el marco de la sesión solemne del Consejo Directivo Universitario, el viernes 7 de octubre de 2016, por el rector de la UASLP, Manuel Fermín Villar Rubio.
\end{abstract}

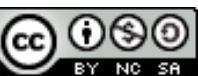

Copyright: (C) 2018 Ribes-Iñesta, I.

Este es un artículo de acceso abierto distribuido bajo los términos de la licencia Creative Commons Reconocimiento-NoComercial-Compartirlgual 4.0 Internacional, por lo que su contenido gráfico y escrito se puede compartir, copiar y redistribuir total o parcialmente sin necesidad de permiso expreso de su autor con la única condición de que no se puede usar con fines directamente comerciales y los términos legales de cualquier trabajo derivado deben ser los mismos que se expresan en la presente declaración. La única condición es que se cite la fuente con referencia a la Revista Digital Internacional de Psicología y Ciencia Social y a su autor. 


\section{INTRODUCCIÓN}

\section{A} ntes que nada, deseo manifestar mi profundo agradecimiento a la Universidad Autónoma de San Luis Potosí por la distinción que me otorga al convertirme, de esta manera, en miembro ad honorem de su claustro. Mi reconocimiento es doble, porque debo confesar que ha sido una gratísima sorpresa que se me postulara para tal distinción, considerando que mi última colaboración con la universidad tuvo lugar en 1978, hace casi 40 años, y porque siempre he guardado un especial afecto y admiración por la cultura potosina.

Desde los 15 años (hace ya casi 60 ) mi vida ha estado ligada a la universidad pública, ya sea como estudiante o como profesor e investigador, siempre con la actitud permanente de considerarme un aprendiz. En el transcurso de estos años las universidades (y el sistema educativo) en México han cambiado profundamente $y$, para ser sincero, no tengo certeza de que haya sido para bien. He vivido directamente las transformaciones de la vida universitaria, una mayoría de ellas cobijadas bajo la bandera de la racionalización y modernización del sistema educativo nacional. No puedo permanecer indiferente ante las verdaderas razones y naturaleza de estos cambios, y voy a abusar de la hospitalidad que me procura la Universidad Autónoma de San Luis Potosí para expresar mi preocupación e inconformidad con el actual estado de cosas. No hay foro más apropiado para hacerlo que el de esta universidad, vanguardia histórica de la autonomía en nuestro país.

La situación de la universidad mexicana no es, ni puede ser, ajena a las circunstancias configuradas por el sistema económico y político mundial. A partir de 1988 se hizo patente la uniformidad impuesta globalmente por el capitalismo como sistema único, y la instauración de la doctrina neoliberal que considera al planeta (por el momento) como un gran mercado abierto a la compe- tencia de los emprendedores, mercado en el que todo es susceptible de convertirse en mercancía y, por consiguiente, de aumentar y acumular, sin freno en el horizonte, las ganancias de las grandes corporaciones y sus cabilderos. Al comercio e industria tradicionales se han sumado el agotamiento y la contaminación de los recursos naturales, el aprovechamiento especulativo de los desastres naturales y los provocados, el lucro con las enfermedades y el hambre, la explotación laboral de las migraciones humanas, la promoción de las guerras como un negocio de destrucción y reconstrucción, la especulación financiera con fondos inmobiliarios y de inversiones, el sometimiento y modulación de la opinión pública por los medios electrónicos e informáticos, la transformación de las personas en consumidores permanentes de bienes desechables, y la privatización de la educación para integrarla al sistema meritocrático del mercado. Se ha perdido la línea divisoria entre lo público y lo privado, de manera que las instituciones públicas se han convertido en agentes e instrumentos servidores del poder económico. Los límites entre la clase política y la clase empresarial son difusos. Los que aparentemente ejercen el servicio público actúan como cabilderos y facilitadores de negocios, recursos y riquezas de las grandes corporaciones y de los aspirantes a constituirlas. Simultáneamente, como se dice en España, entran en acción las puertas giratorias, y los políticos ingresan a las corporaciones al término de sus labores, al tiempo que son remplazados por otros servidores del capital privado en los puestos públicos. Capital y poder político constituyen la nueva simbiosis de nuestra época, en la que se borran también las diferencias entre delincuentes y aplicadores de la ley, y entre terroristas y defensores de la manoseada democracia.

La voracidad sin término del capitalismo que nos toca vivir ha corrompido en un grado nunca antes visto todas las prácticas humanas. En México la corrupción, la simulación, el cinismo y la impunidad se han instalado, con un saldo trágico en todos sentidos, como forma de vida, como cultura de lo cotidiano. Al contrario de lo que afirmó Carlos Fuentes en 1970, las palabras de la clase política no solo 
no han recuperado su transparencia, sino que han perdido toda credibilidad. La gran mayoría de nuestros políticos y empresarios, sin rubor alguno, se burlan, en el día a día, de la realidad que padecemos, y al estilo de los antiguos profetas religiosos, nos repiten que vivimos o estamos a punto de vivir en el paraíso que ellos, afanosamente, con sacrificios y generosidad, contribuyen decisivamente a construir. Para disfrazar sus conductas irresponsables, deshonestas, no comprometidas e irrespetuosas, los poderes económico y político promulgan leyes y reglamentos, crean consejos y comisiones, fiscalías especiales, cuya inviabilidad práctica en algunos casos está asegurada desde su misma concepción y, en otros, cumplen la función a posteriori de justificar sus latrocinios. El país está sobrecargado de leyes que no se cumplen o que solo justifican lo que mal se hace o se hacía, y de organismos ineficientes que forman parte de una larga cadena de trámites diseñados para encubrir desviaciones, anomalías e incumplimientos. La simulación así construida nutre adicionalmente a la corrupción y descomposición del sistema político y social, a la vez que crea una clase parasitaria de funcionarios, encargada de administrar y planificar el país simulado

La educación en general, y en particular la educación superior y la investigación científica y tecnológica, son también apetecibles presas para este sistema predador. La educación básica en México nunca rompió completamente sus vínculos con la Iglesia católica y diversos grupos culturales o económicos conservadores. La escuela privada se contempló como un complemento de la escuela pública para ampliar la cobertura educativa y que, es justo mencionarlo, en algunos casos no se persiguieron únicamente objetivos comerciales. La educación superior inició de manera acelerada su privatización a partir de 1988, no solo por la autorización incontrolada de instituciones privadas ofreciendo estudios de licenciatura y de postgrado, sino también por la adopción de criterios de planeación y administración de la educación superior pública y de la ciencia y tecnología afines a los intereses de las clases detentadoras del poder económico y político. Estas políticas fueron impulsadas por las corporaciones financieras, industriales y comerciales nacionales e internacionales. A partir de la última década del siglo pasado se hizo patente la injerencia de organismos financieros y económicos internacionales, como la OCDE y el Banco Mundial, en la formulación de las directrices a seguir por las universidades públicas mexicanas, tanto en sus pro- gramas formativos como en los programas de investigación. Dichas políticas fueron impuestas a la educación pública por medio de las secretarías de Estado del gobierno federal que suministran y regulan los subsidios económicos, así como por el CONACYT y organismos aparentemente autónomos como la ANUIES. El PRODEP y sus dos ancestros, los PIFIS, la acreditación de programas, la implantación de currículos denominados flexibles en las licenciaturas, los programas de estímulo al desempeño, y muchas otras formas de la llamada cultura de la evaluación, no constituyen iniciativas de las universidades, y ni siquiera de las instituciones gubernamentales mexicanas. Son todas ellas variantes o aplicaciones directas de "recomendaciones" de los organismos internacionales mencionados. Estas políticas han creado una "nomenklatura" administrativa de la educación superior y la investigación científica, cuya justificación operativa ha degenerado en una compulsión permanente en cambiar formatos evaluativos y requerimientos administrativos (lo que ha sido facilitado por una de sus variaciones mutantes, los ingenieros informáticos). Esta nueva "nomenklatura" de planeadores y administradores de la educación superior y la ciencia se ha apropiado de la organización y funcionamiento de las universidades, usurpando su gobernanza en detrimento de los auténticos criterios y modos que sustentan la vida académica y de búsqueda del conocimiento. Se ha constitutito una nueva clase de funcionarios de la ciencia y la educación superior, que al igual que la clase política, van de un cargo a otro en la red cada vez más densificada de control y administración, independientemente de su especialidad y experticia profesional original.

La vida académica y de investigación se ha convertido en patrimonio de una clase de administradores ajenos a ella y a su práctica, la que para algunos es solo el vestigio de un pasado remoto. De esta manera, investigadores y docentes constituyen solamente la materia prima de cálculos, controles, registros, reglamentos, planes, programas y estadísticas diversas. Los académicos son contemplados, contradictoria y simultáneamente, como gasto corriente y como gasto de inversión, para utilizar la jerga economicista de los nuevos tiempos. Las universidades son vistas como empresas que forman parte de la estructura productiva del sistema y, en esa medida, toda inversión debe justificarse con base en su productividad y en la plusvalía que ge- 
nera. El discurso oficial hace manifiesto que gastar en educación es invertir, y que la educación es la instancia en que se crean los recursos humanos para el sistema productivo. En este aspecto es el único en el que no hay engaño. Pero como parte que somos de la periferia del sistema capitalista, esta visión también condena a nuestras universidades a un papel periférico en la generación, transmisión y aplicación del conocimiento: solo maquilamos y reproducimos conocimiento o sus aplicaciones. En las universidades del hemisferio norte, centro del sistema capitalista y el poder económico-financiero, las universidades tienen la libertad de organizarse de manera autónoma, aunque no ostenten la autonomía como atributo y, a pesar de las contradicciones que pueden caracterizarlas, las funciones de los académicos no están sometidas a un escrutinio burocrático permanente como ocurre en las nuestras. En las universidades mexicanas, administrar es usualmente sinónimo de controlar, vigilar, desconfiar y utilizar los subsidios de manera discrecional y vertical. Algunas de nuestras instituciones de educación superior son émulas del "hermano mayor" o "gran hermano" de Orwell en 1984, en las que se usa el "neolenguaje" de la infinidad de siglas referidas a tipo de instituciones, programas, presupuestos y otros más, y en las que hay multitud de instancias administrativas (algunas de ellas con disfraz académico) que funcionan como "policías del pensamiento". La llamada cultura de la evaluación ha resultado ser un gran panóptico, como el que diseñó Jeremy Bentham para vigilar a los reclusos de una prisión en cualquier punto en el que estuvieran: se deben rendir informes permanentemente, se debe justificar cualquier solicitud o petición exhaustivamente, se deben presentar comprobantes de cualquier actividad o resultado, se puede ser auditado in situ para que ese gran ojo se cerciore del cumplimiento o incumplimiento de las tareas académicas. El académico tiene que dedicar una parte de su tiempo a cumplir tareas del proceso de evaluación y, otro, a realizar tareas para ser evaluado, de manera análoga a como los dioses condenaron a Sísifo a rodar sin cesar una roca hasta la cima de una montaña, para que esta volviera a caer por su propio peso. Albert Camus señalaba que "[los dioses] habían pensado con alguna razón que no hay castigo más terrible que el trabajo inútil y sin esperanza". Los nuevos dioses que rigen las universidades han convertido a un posible paraíso del conocimiento en un infierno administrativo.

La academia siempre se debe ceñir a tiempos, formas y criterios de la administración y, aunque se pregona la libertad de cátedra, se departamentalizan o uniforman programas y exámenes, la libertad de investigación se constriñe a la productividad requerida para tener una mejor remuneración, y se debe ser productivo en cantidad para recibir un pago a destajo como en las empresas, se debe publicar con frecuencia para recibir una compensación que nivele decorosamente el salario, y se debe hacerlo además en revistas con impacto, efecto regulado por empresas privadas que deciden qué ciencia es significativa y qué ciencia no lo es con base en criterios de mercado y de las propias revistas que publican. No es importante lo que se publica, sino el ISSN, el ISBN y el índice de impacto correspondiente. En este mercado de la ciencia participan también los programas de postgrado que, a cambio de un puñado de lentejas (las becas para sus estudiantes), se ven obligados a cumplir con criterios de eficiencia productiva en términos del número y proporción de egresados, de su vinculación con el sistema productivo o de prestación de servicios, y su incorporación a la red internacional de producción del conocimiento, supongo que para facilitar lo que en inglés se denomina el scouting de prospectos a pasar de las ligas menores a la liga principal en que se desarrolla el juego del conocimiento. Paradójicamente, con excepciones contadas, nunca se avalúa la calidad, originalidad y relevancia del conocimiento generado y transmitido, pues eso requeriría de jueces auténtica"La llamada cultura de la evaluación ha resultado ser un gran panóptico, como el que diseñó Jeremy Bentham [...] se deben rendir informes permanentemente, se debe justificar cualquier solicitud o petición exhaustivamente, se deben presentar comprobantes de cualquier actividad o resultado, se puede ser auditado in situ para que ese gran ojo se cerciore del cumplimiento o incumplimiento de las tareas académicas." del ejército de reserva del sistema, y nada más.

Esta falsa cultura de la evaluación se ha limitado a otorgar certificaciones que nada significan, y que encubren y promueven prácticas clientelares, simulación y corrupción diversas para satisfacer los indicadores que ena- 
jenan y pervierten la naturaleza misma de toda actividad académica y de conocimiento. Se ha invertido la relación medio-fin: ahora se investiga para publicar y se enseña para graduar estudiantes en vez de publicar cuando se ha investigado algo pertinente en el contexto de una disciplina, y graduar un estudiante cuando domina el campo en el que ha sido aprendiz. No sorprende, por tanto, que en México tengamos investigadores que investigan como si participaran en una cadena de producción, doctores que poco saben y dominan, programas de postgrado en los que no se realiza investigación como actividad sustantiva, publicaciones científicas con impacto solamente en los índices especializados que carecen de repercusión en el avance de las ciencias correspondientes, y multitud de cifras oficiales que, como en todos los ámbitos de la vida nacional, nos quieren hacer creer que hay avances en donde hay retroceso o estancamiento.

La simulación mediante indicadores no oculta la falta de apoyo y el deterioro gradual que sufren la educación superior y la investigación científica en el país. Por tercer sexenio consecutivo no se ha alcanzado la meta propuesta de destinar el $1 \%$ del PIB a la ciencia y, de hecho, en términos relativos, los apoyos reales han disminuido no solo en cuantía sino también en su asignación a proyectos alejados del desarrollo de una infraestructura y programas de investigación sólidamente fundamentados. En la educación superior los subsidios en términos reales se han reducido; se han incrementado las matrículas simplemente con criterios de cobertura demográfica, y no se ha logrado fijar mínimos destinados a la consolidación y desarrollo de las universidades. Se utilizan criterios clientelares por medio de subsidios especiales, y continuamente se viola la autonomía, como atribución constitucional, al etiquetar los presupuestos e incluso verificar los reglamentos universitarios que regulan su ejercicio, como ocurre, entre otros, en los programas de estímulos al desempeño académico cuyos reglamentos deben pasar por la censura de las secretarías de Educación Pública y de Hacienda. Las previsiones a futuro no son halagüeñas. La ANUIES, que debería ser un organismo defensor de la autonomía universitaria, ha elaborado una propuesta de nueva ley de la Educación Superior que se encamina en sentido contrario a su vocación obligada. En la nueva ley se incluye a las universidades privadas como parte del sistema nacional de educación superior, con los mismos derechos de apoyos federal y estatal que las universidades públicas, y no solo eso; la nueva legislación amenaza con crear un nuevo organismo dedicado a la evaluación de la educación superior. Obviamente no se trata de una idea propia de la ANUIES, sino de una imposición desde el poder: la UNAM recién anunció la creación de su propio consejo de evaluación educativa. Ninguna de estas propuestas han sido consultadas, discutidas o siquiera informadas a los miembros de las universidades que se suponen están representadas en la ANUIES, académicos y estudiantes, y constituyen un paso adicional en la privatización de la educación superior.

La privatización de la universidad pública tiene que ver fundamentalmente con la privatización de sus funciones sustantivas, sin que se alteren los aspectos formales de su organización. Una parte del proceso de privatización ha culminado con éxito al someter la vida académica y científica a criterios de eficiencia empresariales, mediante la cultura de la evaluación. Las actividades involucradas en la generación, transmisión y creación del conocimiento, de naturaleza colectiva, se han fragmentado mediante la instauración de un sistema meritocrático de retribuciones y reconocimientos de carácter individual. Con supuestos afanes de innovación y flexibilidad se ha fragmentado igualmente la articulación de los distintos dominios de conocimiento y se ha favorecido una formación restringida y dirigida a distintos nichos del mercado. La siguiente fase del proceso se ha iniciado ya mediante los programas de vinculación e internacionalización. Estos últimos al margen de la gran cantidad de convenios de colaboración ficticios y el turismo de funcionarios que promueven, van articulando de manera progresiva a los académicos y proyectos destacados en la universidad pública con los programas "madre" correspondientes en las instituciones, organizaciones y empresas de los países capitalistas avanzados. Por su parte, los programas de vinculación constituyen hoy día uno de los ejes de la evaluación universitaria, y 
promueven activamente que los grupos y proyectos académicos justifiquen su razón social de ser mediante la prestación de diversos servicios al sistema productivo y, en segundo lugar, al sector público, como un apéndice que subsane su ineficiencia estructural.

La privatización de la universidad significa la privatización del conocimiento, de los criterios de su generación y aplicación, y el acotamiento y restricción de su transmisión. Privatizar la universidad es individualizar lo que por naturaleza es colectivo y, como resultado, cancelar la posibilidad de la universidad como un espacio de conocimiento autónomo, crítico y riguroso, para transformarlo en un conjunto segregado de unidades ar- ticuladas con y por las demandas del sector productivo y la clase en el poder. La privatización de las universidades representa finalmente la apropiación por una minoría del proceso colectivo de generar, transmitir y aplicar el conocimiento como un bien público. Está en manos de los universitarios revertir este proceso, y para ello primero debemos ser conscientes de las funciones a las que nos debemos, de las condiciones que las coartan, y de la necesidad de ser congruentes con la responsabilidad que nos impone nuestra situación privilegiada en un país doliente y saqueado como México.

\section{Emilio Ribes Iñesta}

